\title{
Sodium cantharidinate induces HepG2 cell apoptosis through LC3 autophagy pathway
}

\author{
RAN TAO ${ }^{1,2^{*}}$, WEN-YI SUN ${ }^{2 *}$, DE-HAI YU ${ }^{3}$, WEI QIU ${ }^{4}$, WEI-QUN YAN ${ }^{2}$, \\ YAN-HUA DING ${ }^{5}$, GUANG-YI WANG ${ }^{4}$ and HAI-JUN LI ${ }^{1,4}$ \\ ${ }^{1}$ Institute of Translational Medicine, the First Hospital of Jilin University; ${ }^{2}$ Department of Clinical Pharmacy \\ and Pharmaceutical Management, School of Pharmaceutical Sciences, Jilin University, Changchun, \\ Jilin 130021; ${ }^{3}$ Cancer Center, the First Hospital of Jilin University, Changchun, Jilin 130061; \\ ${ }^{4}$ Department of Surgery, the First Hospital of Jilin University; ${ }^{5}$ Phase I Clinical Research Center, \\ the First Hospital of Jilin University, Changchun, Jilin 130021, P.R. China
}

Received January 19, 2017; Accepted June 20, 2017

DOI: $10.3892 /$ or.2017.5779

\begin{abstract}
The function of sodium cantharidinate on inducing hepatocellular carcinoma cell apoptosis was investigated for the first time. Sodium cantharidinate inhibits HepG2 cell growth mainly by LC3 autophagy pathway. MTT results show that sodium cantharidinate effectively inhibits the proliferation of HepG2 cells in a dose- and time-dependent manner and induce cell apoptosis by caspase-3 activity. The further western blotting and FACS detection show that sodium cantharidinate initiates HepG2 cell autophagy program by LC3 pathway. Autophagy-specific inhibitor 3-MA reduce sodium cantharidinate-induced caspase- 3 activity and HepG2 cell apoptosis. Silence of the LC3 gene in HepG2 cell lines also reduce sodium cantharidinate-induced cell apoptosis. Collectively, our data indicate that sodium cantharidinate induces HepG2 cell apoptosis through LC3 autophagy pathway. Sodium cantharidinate has potential for development as a new drug for treatment of human HCC.
\end{abstract}

\section{Introduction}

The incidence of hepatocellular carcinoma (HCC) is becoming the second leading cause of cancer-related death worldwide, which accounting for approximately 800,000 deaths every year (1). Hepatic resection and liver transplantation have progressed in surgical procedures for HCC. The improved outcomes are limited because of the frequent recurrence, even after liver transplantation (2-5). Thus, it is urgent to develop

Correspondence to: Dr Hai-Jun Li, Institute of Translational Medicine, the First Hospital of Jilin University, 71 Xinmin St., Changchun, Jilin 130021, P.R. China

E-mail: hjli2012@jlu.edu.cn

*Contributed equally

Key words: sodium cantharidinate, autophagy, LC3, HepG2 novel approaches for hepatocarcinoma prevention and treatment. At present, chemotherapy is also a focus for tumor treatment (6). Sorafenib, the molecular targeting agent, was reported to improve survival rates and outcomes in patients with non-resectable or early stage $\operatorname{HCC}(7,8)$. However, sorafenib is the only approved molecular targeted treatment for advanced HCC. Other targeted agents are under investigation. Trials comparing new agents in combination with sorafenib are ongoing. Combinations of systemic targeted therapies with local treatments are being evaluated for further improvement in HCC patient outcomes (9-11).

In recent years, increased data concerning the traditional Chinese medicine with a remarkable activity on the influence with tumor cell death pathway could guide tumor treatment decisions and clinical management (12). Cantharidin, also together with its acid form cantharidinate, was first extracted from Chinese blister beetle, have been used in traditional Chinese medicine for many years $(13,14)$. Sodium cantharidinate has powerful antitumor activity proved in clinical practices in recent years (15). The compound directly inhibits multiple malignant tumors, including myeloma, oral buccal carcinoma, leukemia, gastric cancer, Colo205 CRC, and has low toxic/adverse effects so far (16). In recent years, researchers have confirmed through in vitro experiments that sodium cantharidinate and its derivatives directly kill liver cancer cell lines (17).

Autophagy is the natural, destructive cellular mechanism that degrades damaged proteins and cytoplasm components in lysosomes and thus maintains cellular homeostasis and supplies substrates for energy generation. It is a critical pathway for homeostasis, development and other pathophysiological processes (18). Autophagy plays an important role in the healthy and diseased liver $(19,20)$. Autophagy is considered as an important cellular metabolic process (21). Its function on cell fate is double-edged, which can promote cell survival, therefore may also promote cell death via different mechanisms (22). Autophagy plays different roles depending on the drug, cell type or time of drug action, and the mechanism is not fully understood $(23,24)$. Therefore, the study of the dual role of autophagy may provide new clues for tumor treatment. 
In the present study, we investigated whether sodium cantharidinate induces the HepG2 cell line apoptosis and whether it depends on the autophagy pathway.

\section{Materials and methods}

Reagents. Sodium cantharidinate, Hoechst 33258, MTT and RNase were purchased from Sigma (St. Louis, MO, USA). Z-DEVD-FMK (HY-12466, Caspase-3 inhibitor) was purchased from MedChem Express (Monmouth Junction, NJ, USA). Propidium iodide and Annexin V-FITC Apoptosis Detection kit was purchased from BD Biosciences (San Jose, CA, USA). LC3 siRNA reagent kit was purchased from Cell Signaling Technology (Danvers, MA, USA). Dulbecco's modified Eagle's medium (DMEM), trypsin, fetal bovine serum (FBS), PBS, penicillin and streptomycin were obtained from Gibco BRL Life Technologies (Grand Island, NY, USA).

Preparation of sodium cantharidinate. Sodium cantharidinate was dissolved in PBS ( $\mathrm{pH}$ 7.2) to prepare a stock solution at a concentration of $1.0 \mathrm{mM}$ which was stored at $-20^{\circ} \mathrm{C}$. DMEM complete medium was added to dilute the sodium cantharidinate to the appropriate concentrations prior to use.

HepG2 cell culture and treatment. HepG2 cells were routinely cultured in DMEM complete medium which contains $50 \mathrm{U} / \mathrm{ml}$ antibiotics and $10 \%$ fetal bovine serum (FBS) under the conditions of $5 \% \mathrm{CO}_{2}$ at $37^{\circ} \mathrm{C}$ in cell incubator (HERAcell 150i; Thermo Fisher Scientific, Waltham, MA, USA). Following trypsinization to passage the cells in $75 \mathrm{~T}$ flask 3-5 days, the cells were counted and reseed in 96-well plate in DMEM complete medium without or with sodium cantharidinate for MTT array or apoptosis detection.

The effect of sodium cantharidinate on HepG2 proliferation. The inhibitory effect of sodium cantharidinate on the proliferation of HepG 2 cells were detected via MTT assays. All experiment steps were performed following the instructions of the kit. Briefly, the cells were seeded on 96-well plates at a density of $5 \times 10^{4} / \mathrm{ml}$ at a volume of $200 \mu \mathrm{l}$ per well. All groups without or with sodium cantharidinate $(0,2.0,5.0,12.5 \mu \mathrm{M})$ were incubated 6-24 h. MTT $(1.0 \mathrm{mg} / \mathrm{ml})$ was added to each well, and the cells were incubated for $4 \mathrm{~h}$. The MTT solution was then aspirated, and $100 \mu \mathrm{l}$ DMSO was added. The 96-well plates were read using a microplate spectrophotometer (Synergy H1, BioTek, Winooski, VT, USA) at $540 \mathrm{~nm}$. The experiments were repeated in triplicate. The inhibition percentage was calculated as (1 - the value in experimental group / the value in the control group) x $100 \%$.

FCM for cell apoptosis. Annexin V-FITC and PI double staining flow cytometry analyses were employed. The HepG2 cells were plated in 96-well plates containing $200 \mu \mathrm{l}$ medium at a density of $5 \times 10^{4}$ cells/well. The induction of apoptosis in the HepG2 cells were examined without or with sodium cantharidinate $(5.0 \mu \mathrm{M})$. After culture, the cells were collected in $1.5 \mathrm{ml}$ centrifuge tubes, washed three times with cold PBS and binding buffer, and then stained with Annexin V-FITC and PI (Annexin V-FITC Apoptosis Detection kit; BD Biosciences) for apoptosis detection. Briefly, HepG2 cells in centrifuge tubes were re-suspended in binding buffer. Then, $5 \mu \mathrm{l}$ of FITCAnnexin $\mathrm{V}$ was added to the tubes, which were incubated for 10 min followed by the addition of $5 \mu \mathrm{l}$ PI. The samples were then incubated with PI for another $15 \mathrm{~min}$ and immediately analyzed using a flow cytometer (FACScan; BD Biosciences) with the Flowjo FACS analysis software. The cells in the different portions represented the different cell states as follows: the late-apoptotic cells were present in the upper right portion, the viable cells were present in the lower left portion, and the early apoptotic cells were present in the lower right portion.

Western blotting. HepG2 cell lysates were separated by SDS-PAGE under non-reducing conditions on a $10 \%$ polyacrylamide gel. The proteins were then transferred onto PVDF membranes (GE Healthcare Life Sciences, Piscataway, NJ, USA) by electroblotting. The membranes were blocked with blocking buffer overnight at $4^{\circ} \mathrm{C}$ and then incubated with the caspase-3, cleaved caspase-3, LC3-I and LC3-II antibodies for $1.5 \mathrm{~h}$ at room temperature. The membranes were then washed by washing buffer six times and incubated with HRP-conjugated secondary antibodies for $1 \mathrm{~h}$. After washing, protein bands were visualized using an enhanced chemiluminescent system (Thermo Fisher Scientific). The primary antibodies used (caspase-3, cleaved caspase-3, LC3-I, LC3-II and $\beta$-actin) were all obtained from Cell Signaling Technology.

Indirect immunofluorescence staining and confocal laser microscopy. Hoechst 33258 (Sigma) were used to assessed apoptotic nuclear changes. After treatment with $5.0 \mu \mathrm{M}$ sodium cantharidinate for $0,6,12$, and $24 \mathrm{~h}$, cells were fixed with $4 \%$ paraformaldehyde, stained with Hoechst 33258 (2 $\mu \mathrm{g} / \mathrm{ml}$ ) for $30 \mathrm{~min}$, washed in PBS, and examined using Olympus FV1000 confocal laser microscopy to reveal cell chromatin condensation. Briefly, HepG2 cells were cultured on coverslips overnight, then treated with $5.0 \mu \mathrm{M}$ sodium cantharidinate for $6 \mathrm{~h}$ and rinsed with PBS at least three times. Cells were fixed for 20 min with $4 \%$ paraformaldehyde after incubation, then permeabilized with $0.1 \%$ Triton $\mathrm{X}-100$ for $5 \mathrm{~min}$, finally blocked with bovine serum albumin. Then incubated with primary antibodies against LC3 (1:50 dilution) overnight at $4^{\circ} \mathrm{C}$, then in FITC/Rhodamine Red-conjugated secondary antibodies (1:400 dilution) (all antibodies, Santa Cruz Biotechnology, CA, USA) for $0.5 \mathrm{~h}$, and stained with Hoechst $33258(2 \mu \mathrm{g} / \mathrm{ml})$ for $2 \mathrm{~min}$, washed with PBS three times, and examined by confocal fluorescence microscopy.

Statistical analysis. All data were analyzed and assessed for significance using the Pearson omnibus normality test. All data are presented as the mean \pm the standard error of the mean. Mean values were compared using paired t-tests (two groups) followed by the Bonferroni correction for multiple comparison tests. p-values $<0.05$ were considered to indicate a statistically significant result. All statistical tests were performed with prism software (GraphPad, San Diego, CA, USA).

\section{Results}

Sodium cantharidinate induces apoptosis in HepG2 cells by caspase-3 activity. HepG2 cells were treated with different 
A

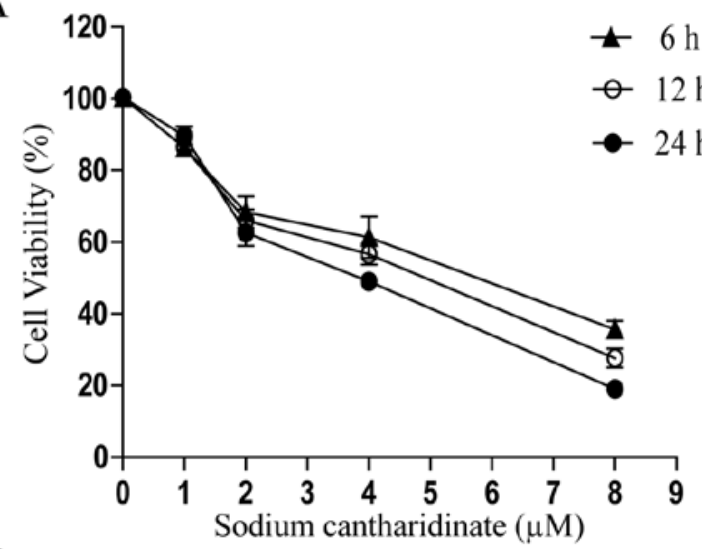

D

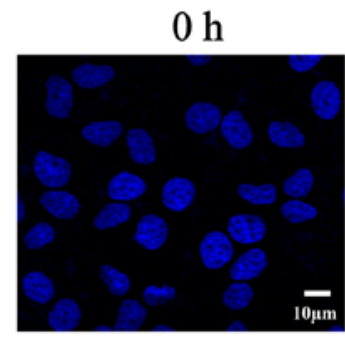

E
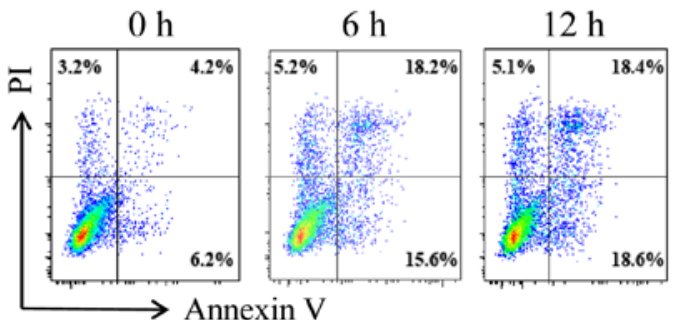

$6 \mathrm{~h}$

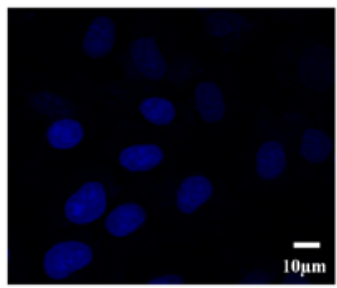

B

Caspase-3
Caspase-3

$\beta$-actin
$17 \mathrm{kDa}$

$35 \mathrm{kDa}$

$43 \mathrm{kDa}$

C

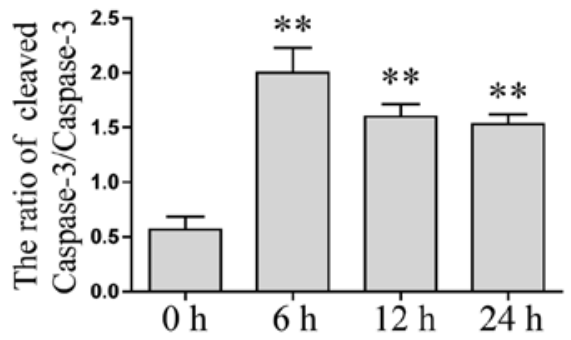

$12 \mathrm{~h}$

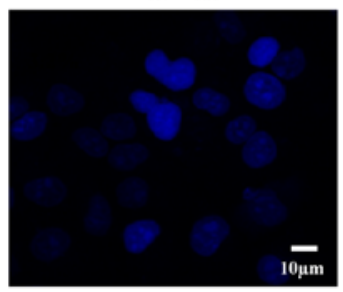

$24 \mathrm{~h}$

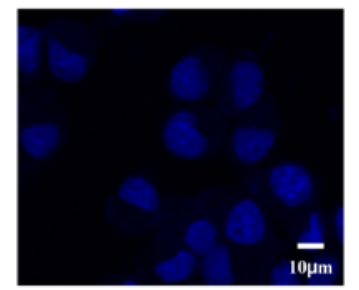

$\mathrm{F}$
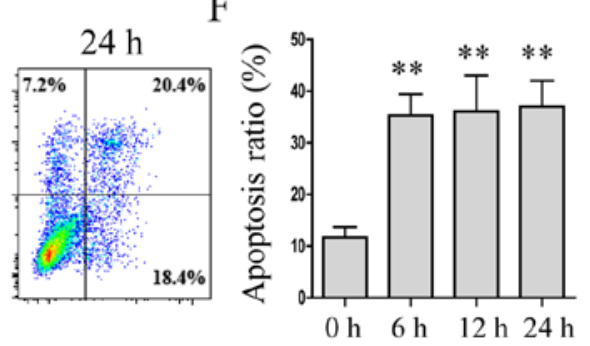

G

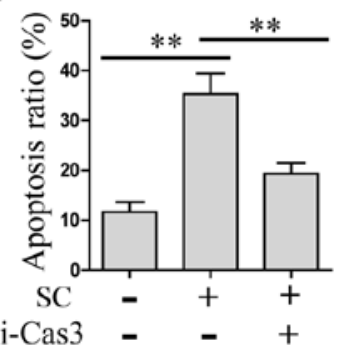

Figure 1. Sodium cantharidinate induces apoptosis of HepG2 cells. (A) HepG2 cells were treated with varying doses of sodium cantharidinate for 6-24 h. Cell viability was determined by MTT assays. (B) Western blot analysis for the expression of caspase-3 and cleaved caspase-3 protein in HepG2 cells treated with $5.0 \mu \mathrm{M}$ sodium cantharidinate. (C) Quantitation of cleaved caspase-3 protein levels ( ${ }^{* *} \mathrm{p}<0.01$, $\mathrm{n}=3$ ). (D) Cells were stained with Hoechst 33258 . Cell morphology was observed by laser scanning confocal microscopy. (E and F) Flow cytometric analysis of apoptosis in HepG2 cells treated with sodium cantharidinate. The cells were exposed to either control solution ( $0.1 \%$ DMSO in medium) or sodium cantharidinate at $5.0 \mu \mathrm{M}$ and incubated for $6-24 \mathrm{~h}$. (G) A caspase-3 inhibitor, Z-DEVD-FMK $(100 \mu \mathrm{M})$ was added to the well, or not. Cells were treated by sodium cantharidinate for $6 \mathrm{~h}$, then apoptosis was determined by FACS. I-Cas3, caspase-3 inhibitor; SC, sodium cantharidinate. The experiments were repeated at least three times. The data are expressed as the means $\pm \mathrm{SD}$ of three experiments $\left({ }^{* *} \mathrm{p}<0.01\right.$ vs. control).

doses of sodium cantharidinate for different time intervals, and MTT results showed that sodium cantharidinate effectively inhibited the proliferation of HepG2 cells in a dose- and time-dependent manner (Fig. 1A). We then selected 5.0 $\mu \mathrm{M}$ sodium cantharidinate for treatment of HepG2 cells at different time intervals, and the apoptotic effector caspase-3 was detected by western blotting. The results showed that the expression of cleaved caspase- 3 was increased at all three time points (4-fold change, $\mathrm{p}<0.01$, Fig. $1 \mathrm{~B}$ and $\mathrm{C}$ ). The cell nucleus stained with Hoechst 33258 was observed using confocal laser scanning microscopy. The results suggested that sodium cantharidinate induced apoptosis in HepG2 cells, which keeps consistency to the MTT array (Fig. 1D). Annexin V-FITC and PI double staining assay was also performed to confirm the cytotoxicity of sodium cantharidinate on HepG2 cells (Fig. 1E and F). The results showed that comparing with the control group, the numbers of early and late apoptotic cells increased significantly in the treated group. The proportion of early and late apoptotic cells in the sodium cantharidinate treatment group reached $37.2 \%$, which was greater than the proportion observed in the control group $(10.1 \%, \mathrm{p}<0.01)$. To determine the effect of caspase- 3 on the sodium cantharidinate inducement of HepG2 cell apoptosis, a caspase-3 inhibitor, Z-DEVD-FMK $(100 \mu \mathrm{M})$ was added to the well, or not. Cells were treated by sodium cantharidinate for $6 \mathrm{~h}$, then apoptosis was determined by FACS. The proportion of apoptotic cells decreased from $35.2 \%$ to $17.8 \%$ when the Z-DEVD-FMK was added (Fig. 1G, p<0.01). This finding indicated that sodium cantharidinate significantly induced HepG2 cell apoptosis by caspase-3 activity.

Sodium cantharidinate induces HepG2 cell autophagy through LC3. Studies suggest that autophagy may be involved in the antitumor effect of drugs (25). Therefore, we analyzed the protein expression of the autophagic maker protein LC3 in response to $5.0 \mu \mathrm{M}$ sodium cantharidinate by western blotting. 
A

$$
\begin{array}{llll}
0 \mathrm{~h} \quad 6 \mathrm{~h} & 12 \mathrm{~h} \quad 24 \mathrm{~h}
\end{array}
$$

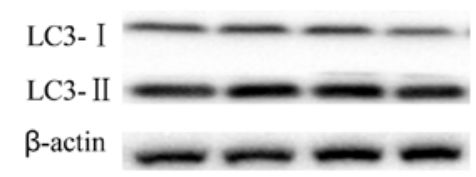
$18 \mathrm{kDa}$ $16 \mathrm{kDa}$ $43 \mathrm{kDa}$

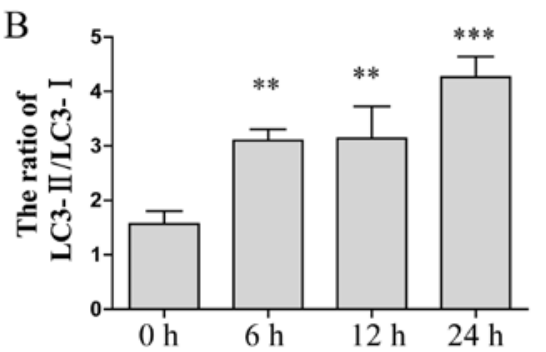

D

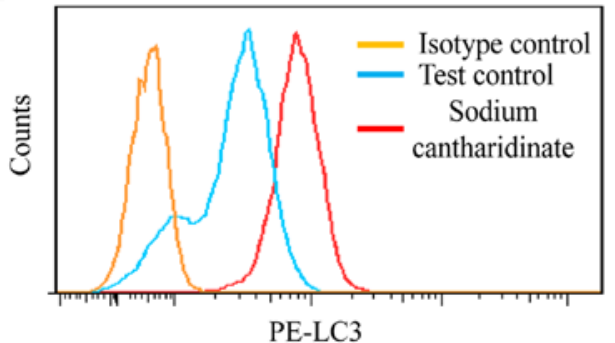

$\mathrm{C}$

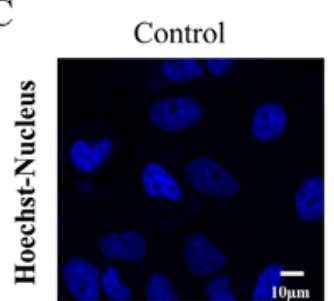
Sodium cantharidinate
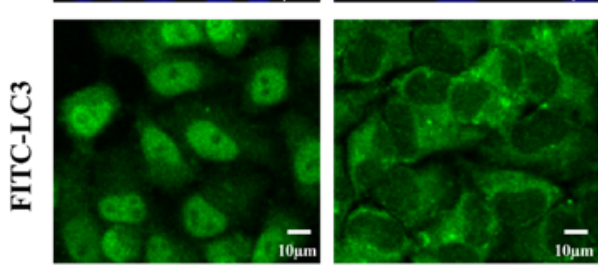

$\mathrm{E}$

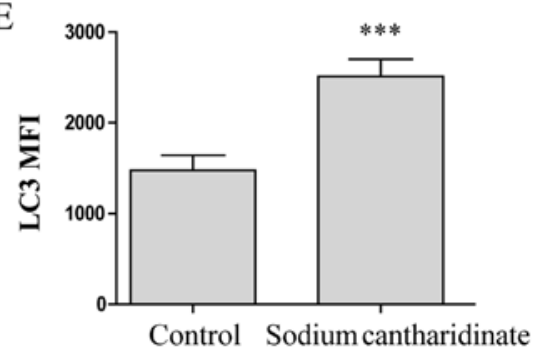

Figure 2. LC3 protein expression in HepG2 cells treated with sodium cantharidinate. (A and B) Western blot analysis and quantitation of the ratio of LC3-II to LC3-I for the expression of LC3 in HepG2 cells treated with $5.0 \mu \mathrm{M}$ sodium cantharidinate for $6 \mathrm{~h}$. ( $\left.{ }^{* *} \mathrm{p}<0.01, \mathrm{n}=3\right)$. (C) HepG2 cells were stained with Hoechst 33258 and LC3-FITC. Cell morphology was observed by laser scanning confocal microscopy. (D and E) Flow cytometric analysis of LC3 expression in HepG2 cells treated with sodium cantharidinate. The HepG2 cells were exposed to either control solution (0.1\% DMSO in medium) or sodium cantharidinate at $5.0 \mu \mathrm{M}$ and incubated for $6 \mathrm{~h}$. The data are expressed as the means $\pm \mathrm{SD}$ of three experiments $\left({ }^{* * *} \mathrm{p}<0.001 \mathrm{vs}\right.$. control).

A

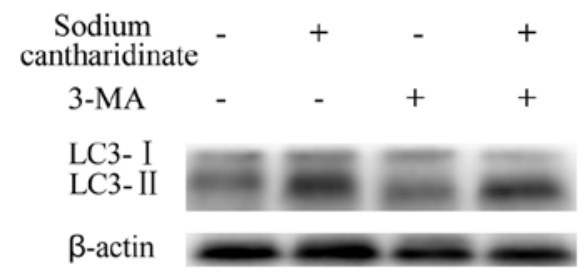

$18 \mathrm{kDa}$

$16 \mathrm{kDa}$

$43 \mathrm{kDa}$

C
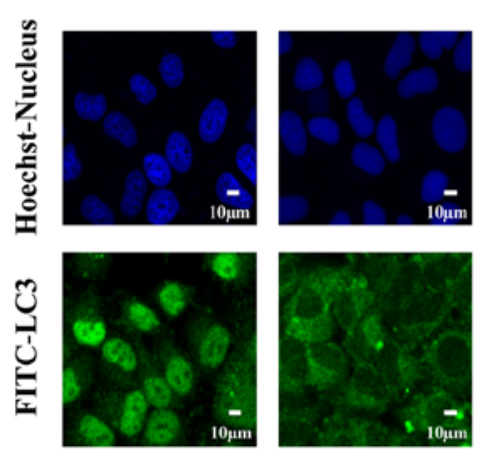

Sodium cantharidinate

3-MA
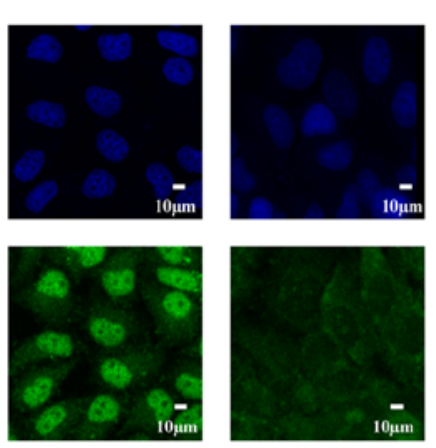

$+$

$+$
B

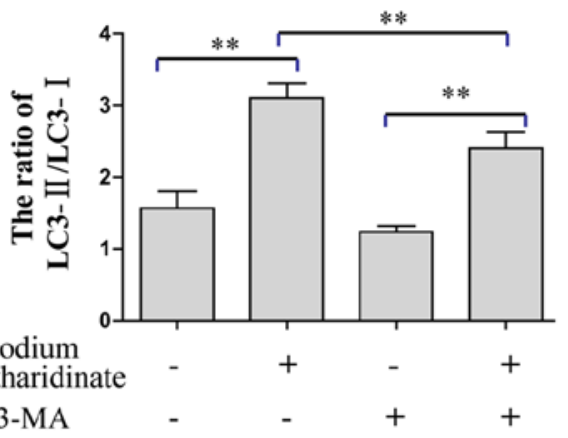

D

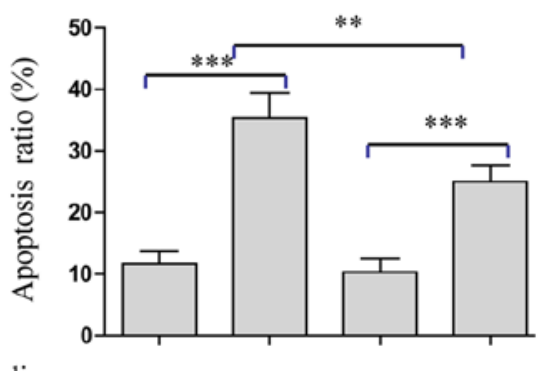

Sodium cantharidinate

3-MA

Figure 3. Inhibition of autophagy reduces sodium cantharidinate-induced cell apoptosis. (A) Western blot analysis for the protein expression of LC3-II to LC3-I for the expression of LC3 in HepG2 cells treated with 5.0 $\mu \mathrm{M}$ sodium cantharidinate combined with 3-MA for $6 \mathrm{~h}$. (B) Quantitation of the ratio of LC3-II to LC3-I. Data are presented as means \pm SD, compared with the control group ( $* * 0<0.01, n=3)$. (C) HepG2 cells were stained with Hoechst 33258 and LC3-FITC. Cell morphology was observed by laser scanning confocal microscopy. (D) Flow cytometric analysis of apoptosis in HepG2 cells treated with sodium cantharidinate combined with 3 -MA. The data are expressed as the means \pm SD of three experiments ( $\left({ }^{* * *} \mathrm{p}<0.001 \mathrm{vs}\right.$. control). 
A

si-Scramble

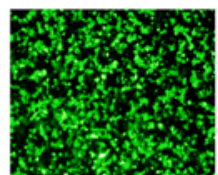

si-LC3

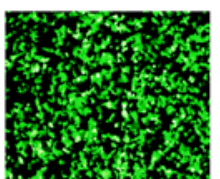

B Control si-Scramble si-LC3

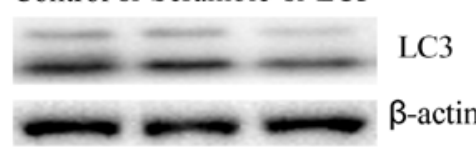

C

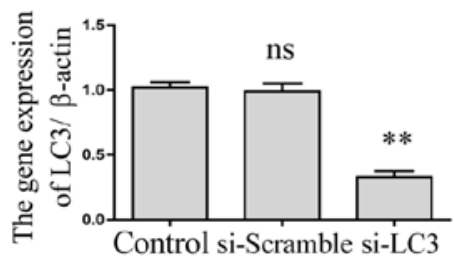

D

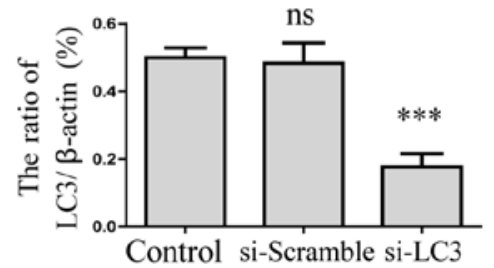

E

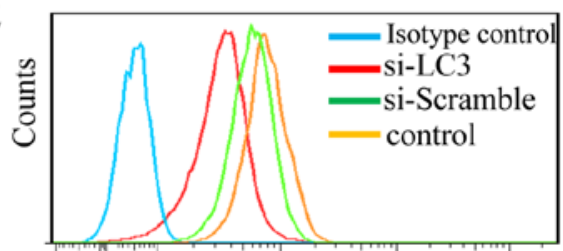

PE-LC3

F

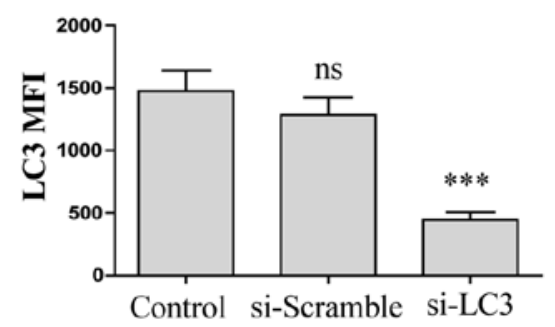

G

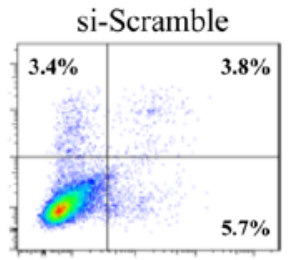

si-Scramble + Sodium cantharidina

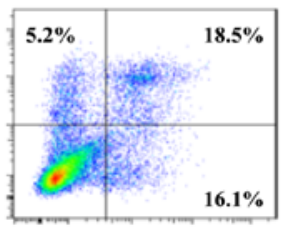

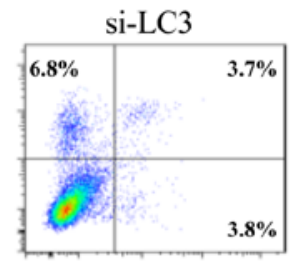

si-LC3 +

Sodium cantharidinate

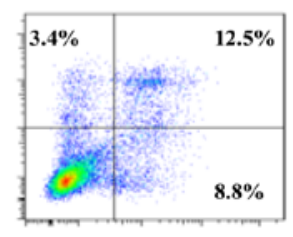

$\mathrm{H}$

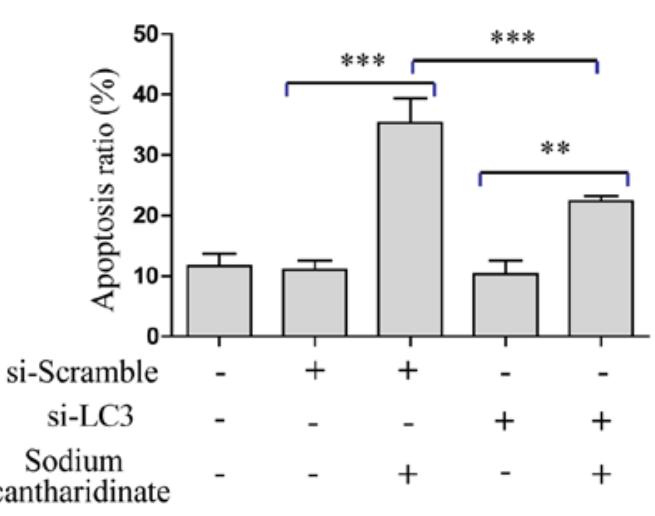

Figure 4. Silence of LC3 inhibits autophagy to reduce sodium cantharidinate-induced cell apoptosis. (A) HepG2 cells were transfected with LC3 siRNA or non-target sequence siRNA (Scramble) for $24 \mathrm{~h}$; GFP expression was observed by fluorescence microscopy. (B) Western blot analysis for the knockdown efficiency of LC3. (C) Relative gene expression of LC3 (** $<<0.01, n=3$ ). (D) Quantitation of the ratio of LC3-II to LC3-I ( ${ }^{* * *} \mathrm{p}<0.001, \mathrm{n}=3$ ). (E and F) Flow cytometric and MFI analysis of LC3 after LC3-siRNA treated HepG2 cells $\left.{ }^{* * *}{ }^{* *}<0.001, n=3\right)$. (G and H) Flow cytometric analysis of apoptosis in HepG2 cells treated with sodium cantharidinate on si-LC3 HepG2 cells or the control HepG2 cells. The experiments were repeated at least three times ${ }^{* * * *} \mathrm{p}<0.001$ vs. control).

The results showed that the protein expression ratio of LC3-II and LC3-I was significantly increased by sodium cantharidinate treatment for 6-24 h (Fig. 2A and B). Furthermore, indirect immunofluorescence showed that LC3 had translocated to the cytoplasm, forming punctate aggregates, and the fluorescence intensity of LC3 was also enhanced (Fig. 2C), suggesting that sodium cantharidinate induced autophagy in HepG2 cells. The expression of LC3 expressed in HepG2 cells was analyzed by flow cytometry. The results are shown in Fig. 2D and E. The LC3 expression level was much higher in HepG2 cells treated with sodium cantharidinate than controls (MFI: $2508 \pm 165$ vs. $1458 \pm 89, \mathrm{p}<0.001)$. These results showed that sodium cantharidinate induced HepG2 cell autophagy through LC3 pathway.

Inhibition of autophagy reduces sodium cantharidinateinduced cell apoptosis. Previous research used 3-MA to inhibit autophagy and prove that autophagy is involved in the growth inhibition of hepatoma cells (26). Therefore, we combined $5 \mathrm{mM} 3-\mathrm{MA}$ and $5 \mu \mathrm{M}$ sodium cantharidinate treatment in HepG2 cells for $6 \mathrm{~h}$, and detected the protein expression of LC3-II and LC3-I by western blotting. Sodium cantharidinate combined with 3-MA resulted in a reduction of protein expression ratio of LC3-II and LC3-I compared with sodium cantharidinate alone (3-fold change, $\mathrm{p}<0.01$, Fig. $3 \mathrm{~A}$ and $\mathrm{B}$ ). Indirect immunofluorescence demonstrated that LC3 was distributed in both the cytoplasm and the nucleus, and the fluorescence intensity was significantly reduced (Fig. 3C), showing that 3-MA inhibited sodium cantharidinate-induced autophagy effectively. Furthermore, Annexin V-FITC and PI double staining assay was also performed to confirm the LC3 inhibitor influences the cytotoxicity of sodium cantharidinate on HepG2 cells (Fig. 3D). The results showed that compared with the control group, the numbers of early and late apoptotic cells decreased significantly when 3-MA was combined with sodium cantharidinate. The proportion of early and late apoptotic cells in the sodium cantharidinate treatment group reached $37.2 \%$, but it decreased to $22.2 \%$ when 3 -MA was added $(\mathrm{p}<0.01)$.

Silence of LC3 inhibits autophagy to reduce sodium cantharidinate-induced cell apoptosis. We applied RNAi technology to inhibit LC3 expression on HepG2 cells. After the LC3 siRNA treatment of HepG2 cells for $24 \mathrm{~h}$, we observed the expression rate of green fluorescent protein (GFP) to be 
$>85 \%$ by fluorescence microscopy (Fig. 4A). LC3 protein expression was significantly decreased as detected by western blotting ( $\mathrm{p}<0.001$, Fig. 4B and C) and qRT-PCR $(\mathrm{p}<0.01$, Fig. 4D). FACS analysis showed that the MFI level of LC3 was also significantly decreased ( $p<0.001$, Fig. 4E and F). Then, Annexin V-FITC and PI double staining assay was also performed to confirm that the LC3 gene was silenced after sodium cantharidinate treatment. The results showed that compared with the control group, the numbers of early and late apoptotic cells decreased significantly when sodium cantharidinate treatment of the LC3 silenced HepG2 cells wre compared to the control cells ( $p<0.001$, Fig. 4G and H). These results showed that LC3 autophagy pathway played an important role in the sodium cantharidinate induced HepG2 cell apoptosis.

\section{Discussion}

The incidence of hepatocellular carcinoma is becoming the second leading cause of cancer-related death worldwide accounting for approximately 800,000 deaths every year. Hepatic resection and liver transplantation have progressed in surgical procedures for HCC. However, the outcomes have improved only slightly because of the frequent recurrence, even after liver transplantation. The pathogenesis on HCC remains unclear, but the genetic mutations of normal cells affected by environmental deterioration or other risk factors become a generally accepted carcinogenic factor (27).

Sodium cantharidinate kills liver cancer cell lines directly, which provided the favorable theoretical basis for the application of treatment of primary liver cancer (17). The present study demonstrated that sodium cantharidinate was able to inhibit the proliferation of HepG2 cells within the ranges of 2.0-12.5 $\mu \mathrm{M}$ and 6-24 h. Sodium cantharidinate enhanced the apoptotic effector of caspase-3 activity and induced cell death. Nucleus stained with Hoechst 33258 and Annexin V-FITC and PI double staining is consistent with MTT results. Caspase-3 activation could be initiated by many upstream signalregulated molecules (28-30). Previous studies suggested that drugs could promote autophagy in human cancer cell lines, prompting speculation that autophagy may be involved in the antitumor effect (26). Some research also demonstrated that oxidative stress can induce autophagy then inhibit the proliferation of liver cancer cells (26). In this study, we found that LC3 punctate aggregates and nucleation appeared in HepG2 cells treated with sodium cantharidinate, indicating that sodium cantharidinate induced autophagy in HepG 2 cells then caused cell death. The results showed that the protein expression ratio of LC3-II and LC3-I was significantly increased by sodium cantharidinate treatment for 6-24 h on HepG2 cells.

To confirm how important autophagy pathway in the sodium cantharidinate induced HepG2 cells apoptosis, the autophagy inhibitor 3-MA was added to the cell culture system to observe sodium cantharidinate-induced apoptosis of HepG2 cells. The results showed that after HepG2 cells were treated with 3-MA, sodium cantharidinate-induced apoptosis of HepG2 cells were reduced greatly. We applied RNAi technology to inhibit LC3 expression. After the LC3 siRNA treatment in HepG2 cells for $24 \mathrm{~h}$, we observed the expression of LC3 protein expression were significantly decreased detected by western blotting. At the same time, the numbers of early and late apoptotic cells decreased significantly. Based on the results, we concluded that sodium cantharidinate performed its antitumor effect by inducing autophagy on target cells. In summary, this study found that sodium cantharidinate acted to inhibit HepG2 cells by inducing autophagy. To our knowledge, this is the first study revealing the exact mechanism of sodium cantharidinate on inducing HepG2 cell apoptosis. Sodium cantharidinate has potential for development as a new drug for treatment of human HCC.

\section{Acknowledgements}

This study was supported in part by grants from the Jilin Provincial Natural Science Foundation of China (no. 20140520014JH), the 4th Young Scientist Fund of Jilin University (no. 2013068), the National Major Scientific, the Technological Special Project for 'Significant New Drugs Development' (no. 2014ZX09303303), the Interdisciplinary Chemistry and Medicine Foundation of Jilin University (JDYYJCHX004) and the National Natural Science Foundation of China (no. 31470418, to Y.H.).

\section{References}

1. Llovet JM, Burroughs A and Bruix J: Hepatocellular carcinoma. Lancet 362: 1907-1917, 2003.

2. Shirabe K, Kanematsu T, Matsumata T, Adachi E, Akazawa K and Sugimachi K: Factors linked to early recurrence of small hepatocellular carcinoma after hepatectomy: Univariate and multivariate analyses. Hepatology 14: 802-805, 1991.

3. Yamashita Y, Morita K, Iguchi T, Tsujita E, Soejima Y, Taketomi A and Maehara Y: Surgical impacts of an en bloc resection of the diaphragm for hepatocellular carcinoma with gross diaphragmatic involvement. Surg Today 41: 101-106, 2011.

4. Sakaguchi T, Suzuki S, Morita Y,Oishi K, Suzuki A,Fukumoto K, Inaba K, Nakamura $S$ and Konno H: Impact of the preoperative des-gamma-carboxy prothrombin level on prognosis after hepatectomy for hepatocellular carcinoma meeting the Milan criteria. Surg Today 40: 638-645, 2010.

5. Taketomi A, Fukuhara T, Morita K, Kayashima H, Ninomiya M, Yamashita Y, Ikegami T, Uchiyama H, Yoshizumi T, Soejima Y, et al: Improved results of a surgical resection for the recurrence of hepatocellular carcinoma after living donor liver transplantation. Ann Surg Oncol 17: 2283-2289, 2010.

6. Nault JC, De Reyniès A, Villanueva A, Calderaro J, Rebouissou S, Couchy G, Decaens T, Franco D, Imbeaud S, Rousseau F, et al: A hepatocellular carcinoma 5-gene score associated with survival of patients after liver resection. Gastroenterology 145: 176-187, 2013.

7. Balkwill $\mathrm{F}$ and Mantovani A: Inflammation and cancer: back to Virchow? Lancet 357: 539-545, 2001.

8. de Visser KE, Eichten A and Coussens LM: Paradoxical roles of the immune system during cancer development. Nat Rev Cancer 6: 24-37, 2006.

9. Posner MR: Paradigm shift in the treatment of head and neck cancer: The role of neoadjuvant chemotherapy. Oncologist 10 (Suppl 3): 11-19, 2005.

10. Bruix J, Gores GJ and Mazzaferro V: Hepatocellular carcinoma: Clinical frontiers and perspectives. Gut 63: 844-855, 2014.

11. Kaseb AO, Abaza YM and Roses RE: Multidisciplinary management of hepatocellular carcinoma. Recent Results Cancer Res 190: 247-259, 2013.

12. Gerber DE: Targeted therapies: A new generation of cancer treatments. Am Fam Physician 77: 311-319, 2008.

13. Honkanen RE: Cantharidin, another natural toxin that inhibits the activity of serine/threonine protein phosphatases types 1 and 2A. FEBS Lett 330: 283-286, 1993.

14. Deng LP, Dong J, Cai H and Wang W: Cantharidin as an antitumor agent: A retrospective review. Curr Med Chem 20: 159-166, 2013. 
15. Tsauer W, Lin JG, Lin PY, Hsu FL and Chiang HC: The effects of cantharidin analogues on xanthine oxidase. Anticancer Res 17: 2095-2098, 1997.

16. Lin LH, Huang HS, Lin CC, Lee LW and Lin PY: Effects of cantharidinimides on human carcinoma cells. Chem Pharm Bull (Tokyo) 52: 855-857, 2004.

17. Yeh CB, Su CJ, Hwang JM and Chou MC: Therapeutic effects of cantharidin analogues without bridging ether oxygen on human hepatocellular carcinoma cells. Eur J Med Chem 45: 3981-3985, 2010.

18. Ravikumar B, Sarkar S, Davies JE, Futter M, Garcia-Arencibia M, Green-Thompson ZW, Jimenez-Sanchez M, Korolchuk VI, Lichtenberg M, Luo S, et al: Regulation of mammalian autophagy in physiology and pathophysiology. Physiol Rev 90: 1383-1435, 2010.

19. Gual P, Gilgenkrantz H and Lotersztajn S: Autophagy in chronic liver diseases: The two faces of Janus. Am J Physiol Cell Physiol 312: C263-C273, 2017.

20. Kim KY, Jang HJ, Yang YR, Park KI, Seo J, Shin IW, Jeon TI, Ahn SC, Suh PG, Osborne TF, et al. Corrigendum: SREBP-2/ PNPLA8 axis improves non-alcoholic fatty liver disease through activation of autophagy. Sci Rep 6: 37794, 2016.

21. Ogier-Denis E and Codogno P: Autophagy: A barrier or an adaptive response to cancer. Biochim Biophys Acta 1603: 113-128, 2003

22. Shintani T and Klionsky DJ: Autophagy in health and disease: A double-edged sword. Science 306: 990-995, 2004.

23. Mariño G and López-Otín C: Autophagy: Molecular mechanisms, physiological functions and relevance in human pathology. Cell Mol Life Sci 61: 1439-1454, 2004.
24. Eskelinen EL: Maturation of autophagic vacuoles in mammalian cells. Autophagy 1: 1-10, 2005.

25. Guan J, Lo M, Dockery P, Mahon S, Karp CM, Buckley AR, Lam S, Gout PW and Wang YZ: The xc-cystine/glutamate antiporter as a potential therapeutic target for small-cell lung cancer: Use of sulfasalazine. Cancer Chemother Pharmacol 64: 463-472, 2009.

26. Guo W, Zhao Y, Zhang Z, Tan N, Zhao F, Ge C, Liang L, Jia D, Chen T, Yao M, et al: Disruption of $\mathrm{xCT}$ inhibits cell growth via the ROS/autophagy pathway in hepatocellular carcinoma. Cancer Lett 312: 55-61, 2011.

27. Bruix J, Reig M and Sherman M: Evidence-based diagnosis, staging, and treatment of patients with hepatocellular carcinoma. Gastroenterology 150: 835-853, 2016.

28. Zhang M, Yan H, Li S and Yang J: Rosmarinic acid protects rat hippocampal neurons from cerebral ischemia/reperfusion injury via the Akt/JNK3/caspase-3 signaling pathway. Brain Res 1657: 9-15, 2017.

29. Venkatesan RS and Sadiq AM: Effect of morin-5'-sulfonic acid sodium salt on the expression of apoptosis related proteins caspase 3, Bax and $\mathrm{Bcl} 2$ due to the mercury induced oxidative stress in albino rats. Biomed Pharmacother 85: 202-208, 2017.

30. Mondal A and Bennett LL: Resveratrol enhances the efficacy of sorafenib mediated apoptosis in human breast cancer MCF7 cells through ROS, cell cycle inhibition, caspase 3 and PARP cleavage. Biomed Pharmacother 84: 1906-1914, 2016. 